\title{
Olgu sunumu: Servikal özofagusta dev inlet patch
}

\author{
Case report: giant inlet patch in cervical esophagus
}

Ahmet UYANIKOĞLU' ${ }^{1}$, Muharrem COŞKUN ${ }^{1}$, Doğan Nasır BINICI², Yunus Ilyas KIBAR ${ }^{2}$

Erzurum Bölge Eğitim Hastanesi, ${ }^{1}$ Gastroenteroloji ve ${ }^{2}$ Iç Hastalıkları Klinikleri, Erzurum

Servikal özofagus yerleşimli heterotopik gastrik mukoza, konjenital bir anomalidir. Semptomlar ve morfolojik değişiklikler, heterotopik gastrik mukozanın salgılamış olduğu asid hasarına bağlıdır. Bu odaktan malign transformasyon ve adenokarsinogenezis de oluşabilmektedir. Bu yazıda, daha önce bu kadar büyük düzeyde görmediğimiz servikal özofagustan torakal özofagusa kadar uzanan dev inlet patch olgusu sunulmuştur.

Anahtar kelimeler: Özofagus, inlet patch, heterotopik gastrik mukoza

\section{GİRİş}

Üst özofagusta heterotopik gastrik mukoza (HGM), ilk olarak 1805 yllında Schmit tarafından konjenital olarak servikal özofagusta gastrik mukozanın yer alması şeklinde tanımlanmıştır (1). Üst özofagusta HGM bütün yaş gruplarında görülebilmekte olup, sıklığı \%0.1 ile \%3.8 oranında bildirilmiştir $(2,3)$. Türkiyede yapılan çalışmalarda inlet patch'ın atlanabileceği, bir çalışmada prevalansının \%3.6 olduğu, yine Türkiyeden Mart 2007- Kasım 2009 tarihleri arasinda 14935 hastaya uygulanan 18522 üst gastrointestinal sistem endoskopisinin retrospektif olarak incelendiği endoskopik özellikler ve HGM'nın histolojik inceleme sonuçlarında hastalardan 60 $(\% 0,4)$ tanesinde HGM saptandığı bildirilmiştir (4-6).

Özofagiyal HGM, embriyolojik dönemde özofageal epitelizasyonun eksik kalması sonrasında gelişen konjenital anomalidir (7). Gestasyonel yaşamın 10. haftasında özofagus tek katlı kolumnar epitel ile döşelidir. Beşinci ayda skuamöz epitel, özofagusun orta $1 / 3$ bölümünde görülmeye başlar ve buradan distal ve proksimale doğru yayılır. Eğer bu işlem tamamlanamazsa, bazı kolumnar hücreler doğumda kalabilmekte, buna bağlı olarak da özofagus üst 1/3'lük bölümünde mideye ait glandlar izlenmektedir (8).

Inlet patch, sıklıkla büyüklüğü 1 cm'i geçmeyen, çok sık görülmeyen doğumsal bir anomalidir. Bu yazıda, servikal özofagustan başlayıp genişleyerek torasik özofagus mukozasına kadar uzanan dev inlet patch olgusu büyüklügü nedeniyle sunulmuş ve literatür eşliğinde tartışılmıştır.
Heterotopic gastric mucosa located in the cervical esophagus is a congenital anomaly. Symptoms and morphologic changes are associated with the destruction caused by the acid secreted from the heterotopic gastric mucosa. Malignant transformation and adenocarcinogenesis may also develop in these foci. In this case report, we present a patient who had a giant esophageal inlet patch, involving a large level of the cervical esophagus extending from the thoracic esophagus.

Key words: Esophagus, inlet patch, heterotopic gastric mucosa

\section{OLGU}

Kırk beş yaşında erkek hasta midede ağrı, şişkinlik, arada sırada ağzına acı, ekşi su gelmesi şikayetleri ile polikliniğimize başvurdu. Yaklaşık 4-5 yıldır şikayetleri olan hastaya gastrit olduğu söylenmiş ve düzensiz proton pompa inhibitörü kullanmış. Hastanın şikayetlerinin devam etmesi üzerine yönlendirilen hastaya üst gastrointestinal endoskopisi yapıldı. Yap1lan gastroskopide ön kesici dişlerden itibaren 20.cm'de başlayıp, 25.cm'e kadar uzanan, lümenin yarısını kaplayan, yaklaşı 2x5 cm çapında düzgün yüzeyli mide mukozası görüldü (Şekil 1-2). Buna ilaveten alt özofagustaki hiperemik alan görülüp mide korpus ve antrumda yaygın erozyonları vardı. Mide antrumdan biyopsi alınarak işlem sonlandırıldı. Hastanın mide antrum mukozasından gönderilen dokunun histopatolojik incelemesinde lamina propriada az sayıda nötrofilin eşlik ettiği plazma hücrelerinden zengin mikst iltihabi reaksiyon ve yüzey müküs katı içerisinde Helicobacter pylori ( $H p$ ) olduğu şeklinde rapor edildi. Hastaya klaritromisin+lansoprazol+amoksisilin 14 gün verildi ve diet başlandı. İki aylık lansoprazol tedavisi sonrasinda gaitada $H p$ antijeni negatif saptandı ve hastanın şikayetlerinde belirgin düzelme olmuştu. Poliklinik ve endoskopi takibi önerilerek hasta takibe alındı.

\section{TARTIȘMA}

Üst özofagusta HGM bütün yaş gruplarında görülebilmektedir ve sık değildir (2-6). HGM, boyut olarak 1 cm'den küçük olabileceği gibi, 5 cm'den de büyük olabilmektedir. Makroskopik olarak, koyu pembe ve kadifemsi bir görünümdedir. Tek bir parça ve/veya multipl parçalar halinde olabileceği gi- 


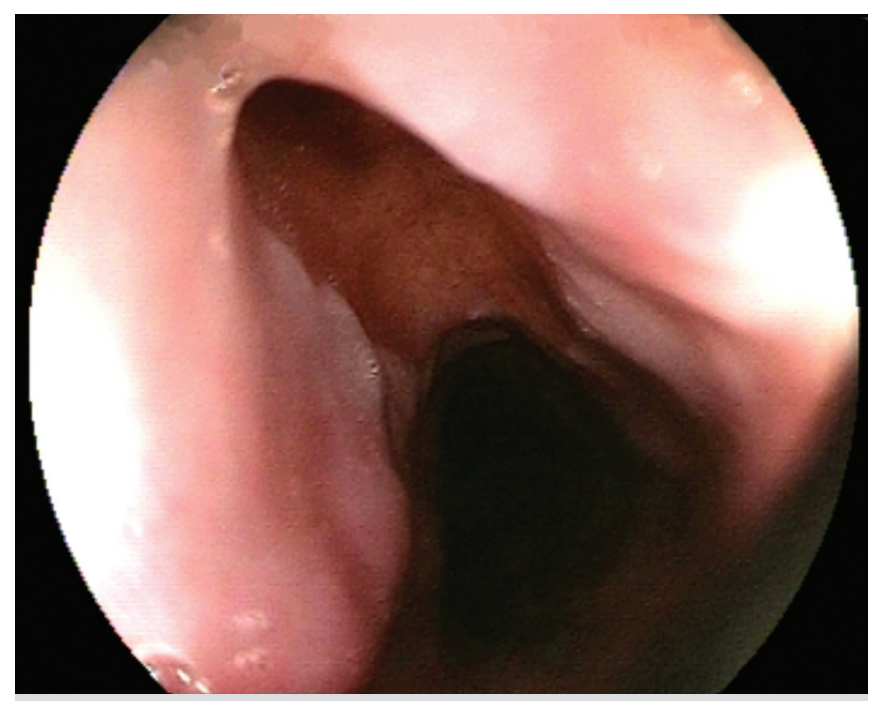

Şekil 1. Inlet Patch (proksimal).

bi, özofagusu sirküler olarak çepeçevre sarabilmektedir (9). Olgumuz orta yaşlı erkek hasta olup, HGM makroskopik olarak koyu pembe renkte ve özofagusu semisirküler olarak saran bir görünümdeydi.

HGM, üst özofagus dışında çok ender olarak dil, ağız tabanı, submandibular bez, ince barsaklar, pankreas, safra kesesi ve Meckel divertikülünde de görülebilmektedir (9-11). Asemptomatik ve insidental olarak tespit olabileceği gibi, erozyon, ülser, stenoz, fistül, intestinal metaplazi, yüksek derecede displazi veya adenokarsinoma gelişimi de olabilmektedir. HGM, Barrett özofagus gelişimi riskini arttırmaktadır. HGM'li hastaların yaklaşık 1/3'ünde ilerleyen dönemde Barrett özofagus gelişmektedir (8-13). Hp infeksiyonu, genelde oral yolla geçiş göstermektedir. Üst gastrointestinal sistem üst kısminda mide mukozasının olması, Hp'nin yerleşmesini kolaylaştırıcı bir zemin oluşturmaktadır (1,12-15). Tang ve arkadaşları yedi yıllık bir dönemde 1821 hastaya yapmış oldukları üst gastrointestinal sistem endoskopisinde, 20 hastada (\%1) HGM saptamışlardır. Lezyon, boyut olarak 5 ile $12 \mathrm{~mm}$ arasındadır ve özofagusun \%10 ile \%20'sini çevrelemektedir (1). Bizim vakamızda komplikasyon gelişmemişti, düzgün yüzeyli olduğundan biyopsi alınmadı. Büyüklük Tang ve arkadaşlarının yaptığı çaışma bulgularına göre belirgin büyüktü. Gastrik biyopside Hp pozitif saptanmıştı. Makroskopik olarak HGM olduğuna karar verildiğinden HGM dokusundan biyopsi alınmamış ve bu dokuda Hp bakılmamıştır.

Yapılan çalışmalar, HGM'nin asit üretebildiğini ve bunun da Hp kolonizasyonu için ideal bir yerleşim alanı olabileceğini

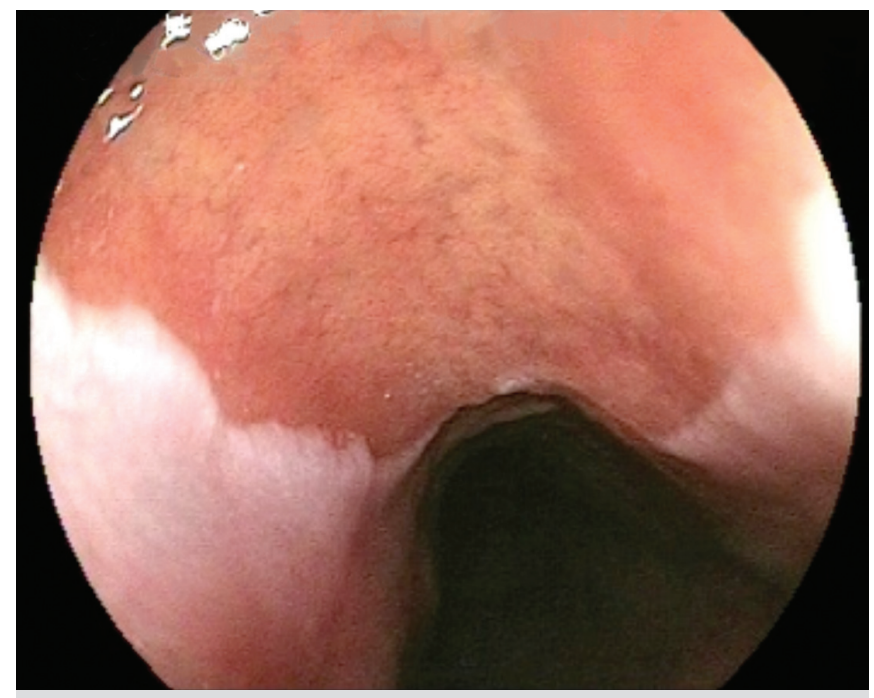

Şekil 2. Inlet patch (distal)

göstermektedir $(16,17)$. HGM, siklikla servikal özofagusta yerleşmekte, lokal olarak cepler, striktürler, ülser ve fistül oluşumuna yol açabilmekte, semptom olarak ağrı, disfaji ve odinofajiye neden olabilmektedir. Semptomatik özofageal HGM'nin patofizyolojisinde esas etken, dokunun o bölgede asit üretmesidir. Semptom, klinik bulgular ve komplikasyonun temelinde yatan etken, olmaması gereken yerde asid salgilanmasıdır (7). Asemptomatik olgularda 24 saatlik $\mathrm{pH}$ profilinin çıkartılması, tanıda yardımcı olmaktadır. Olgumuzda ağrı, en fazla yakındığı şikayetleri arasındaydı. HGM'dan adenokarsinom oluşumu oldukça ender olmakla birlikte, bugüne kadar literatürde tanımlanmış 24 vaka vardır (18). HGM tedavisi için kabul edilmiş standart bir tedavi yoktur. Bazı çalışmalarda sinırlı sayıda olgularda denenmiş olsa da, argon lazer plazma koagülasyonu ile, cerrahi öncesi striktür oluşumunun önlenmesinde başarılı sonuçlar bildirilmiştir. Striktür olan bazı olgularda cerrahi tedavi gerekebilmektedir $(19,20)$. Bizim hastamız dispeptik yakınmalarla ve reflü şikayetleri ile müracaat etmiş ve proton pompa inhibitörlerinden fayda görmemişti. Mide antrum biyopsisinde $H p$ olmasından dolayı eradikasyon tedavisi verilmiş ve kontrolünde $H p$ negatifleşmiştir. Hastanın şikayetlerinde belirgin azalma olmuştur.

Tedaviye rağmen dispeptik şikayetleri devam eden ve reflü şikayetleri olan hastalarda üst gastrointestinal sistem endoskopisi istenmeli ve HGM açısından da araştırılmalıdır. HGM büyüklüğü ortalama 5-12 mm olarak bildirilmesine rağmen bizim vakamızda olduğu gibi dev boyutlarda olabilir. HGM varlığı olan olgular, nadir de olsa adenokarsinom gelişme riskinden dolayı, endoskopik olarak takip edilmelidir. 


\section{KAYNAKLAR}

1. Tang P, McKinley MJ, Sporrer M, Kahn E. Inlet patch: prevalence, histologic type, and association with esophagitis, Barrett esophagus, and antritis. Arch Path Lab Med 2004; 128: 444-7.

2. Jacobs E, Dehou MF. Heterotopic gastric mucosa in the upper esophagus: a prospective study of 33 cases and review of literature. Endoscopy 1997; 29: 710-5

3. Borhan-Manesh F, Farnum JB. Incidence of heterotopic gastric mucosa in the upper oesophagus. Gut 1991; 32: 968-72

4. Korkut E, Bektaş M, Memmedzade F, et al. "Üst GIS Endoskopi Sirasında Inlet Patch Tanısını Atliyor muyuz?" 23.Ulusal Gastroenteroloji Kongresi, 81, Istanbul, Türkiye 2006.

5. Poyrazoğlu OK, Bahçecioğlu IH, Dağlı AF, et al. Heterotopic gastric mucosa (inlet patch): endoscopic prevalence, histopathological, demographical and clinical characteristics. Int J Clin Pract 2009; 63: 287-91.

6. Kekilli M, Sayılır A, Yeşil Y, et al. Servikal özofagustaki heterotopik gastrik mukozanın endoskopik sıklığı; bir referans merkez çalışması. Akademik Gastroenteroloji Dergisi 2009; 8: 119-22.

7. von Rahden BH, Stein HJ, Becker K, et al. Heterotopic gastric mucosa of the esophagus: literature-review and proposal of a clinicopathologic classification. Am J Gastroenterol 2004; 99: 543-51.

8. Lauwers GY, Scott GV, Vauthey JN. Adenocarcinoma of the upper esophagus arising in cervical ectopic gastric mucosa: rare evidence of malignant potential of so-called "inlet patch". Dig Dis Sci 1998; 43: 901-7.

9. Gutierrez O, Akamatsu T, Cardona H, et al. Helicobacter pylori and heterotopic gastric mucosa in the upper esophagus (the inlet patch). Am J Gastroenterol 2003; 98: 1266-70.

10. Mann NS, Mann SK, Rachut E. Heterotopic gastric tissue in the duodenal bulb. J Clin Gastroenterol 2000; 30: 303-6

11. Xeropotamos N, Skopelitou AS, Batsis C, Kappas AM. Heterotopic gastric mucosa together with intestinal metaplasia and moderate dysplasia in the gall bladder: report of two clinically unusual cases with literature review. Gut 2001; 48: 719-23.
12. Berkelhammer C, Bhagavan M, Templeton A, et al. Gastric inlet patch containing submucosally infiltrating adenocarcinoma. J Clin Gastroenterol 1997; 25: 678-81.

13. Korkmaz U, Erdoğmuş B, Akcan Y, et al. Gastrik inlet dokusunda rastlantısal radyasyonun neden olduğu ciddi özofageal benign striktür. Turkiye Klinikleri J Gastroenterohepatol 2009; 16: 21-3

14. Leung WK, Siu KL, Kwok CK, et al. Isolation of Helicobacter pylori from vomitus in children and its implication in gastro-oral transmission. Am J Gastroenterol 1999; 94: 2881-4.

15. Alagözlü H, Simşek Z, Unal S, et al. Is there an association between Helicobacter pylori in the inlet patch and globus sensation? World J Gastroenterol 2010; 16: 42-7.

16. Borhan-Manesh F, Farnum JB. Study of Helicobacter pylori colonization of patches of heterotopic gastric mucosa (HGM) at the upper esophagus. Dig Dis Sci 1993; 38: 142-6.

17. Avidan B, Sonnenberg A, Chejfec G, et al. Is there a link between cervical inlet patch and Barrett's esophagus? Gastrointest Endosc 2001; 53: 717-21.

18. Galan AR, Katzka DA, Castell DO. Acid secretion from an esophageal inlet patch demonstrated by ambulatory $\mathrm{pH}$ monitoring. Gastroenterology 1998; 115: 1574-6

19. Jabbari M, Goresky CA, Lough J, et al. The inlet patch: heterotopic gastric mucosa in the upper esophagus. Gastroenterology 1985; 89: 352-6.

20. Sperling RM, Grendell JH. Adenocarcinoma arising in an inlet patch of the esophagus. Am J Gastroenterol 1995; 90: 150-2. 